TEKA

KOMISJI POLITOLOGII

I STOSUNKÓW MIĘDZYNARODOWYCH

of the COMMISSION OF POLITICAL SCIENCE

AND INTERNATIONAL AFFAIRS 
prof. dr hab. Henryk Chałupczak (UMCS Lublin)

prof. Joana Horga (University of Oradea, Romania), prof. dr hab. Jan Hudzik(UMCS Lublin), prof. dr Maria Monserrat Llario (University of Buenos Aires, Argentina), prof. dr hab. Stanisław Michałowski (UMCS Lublin), prof. dr Marcos Pablo Moloeznik (Guadalajara University, Mexico), prof. dr Slobodan Pajovic (Megatrend University, Serbia), prof. dr Eiiti Sato (University of Brasilia, Brasilia), prof. dr hab. Marek Żmigrodzki (UMCS, Lublin)

Redaktor Naczelny Teki Komisji Politologii i Stosunków Międzynarodowych prof. dr hab. Marek Pietraś (UMCS, Lublin)

Recenzent tomu 12/3 (2017)

Dr hab. Rafał Ożarowski, prof. UG (Uniwersystet Gdański)

Prof. dr hab. Grażyna Michałowska (Uniwersytet Warszawski)

Prof. dr hab. Grzegorz Janusz (Uniwersytet Marii Curie-Skłodowskiej)

Prof. dr hab. Henryk Chałupczak (Uniwersytet Marii Curie-Skłodowskiej)

Dr Agnieszka Rybczyńska (Uniwersytet Marii Curie-Skłodowskiej)

Prof. Huseyin Bagci (Middle East Technical University)

Dr hab. Izabela Oleksiewicz, prof. PRz (Politechnika Rzeszowska)

Dr Kamil Zajączkowski (Uniwersytet Warszawski)

Weryfikacja językowa

w języku angielskim - prof. David Jervis (USA)

Redakcja wydania

Marcin Wachowicz

Projekt okładki

Marta Kwiatkowska

(C) Copyright by Polska Akademia Nauk Oddział w Lublinie, Lublin 2017

(C) Copyright by Uniwersytet Marii Curie-Skłodowskiej, Lublin 2017

Publikacja dofinansowana ze środków Polskiej Akademii Nauk i Wydziału Politologii UMCS

\section{ISSN 1896-8279}

www.pan-ol.lublin.pl

\section{Realizacja wydawnicza, skład i druk}

Wydawnictwo POLIHYMNIA sp. z o.o.

ul. Deszczowa 19, 20-832 Lublin, tel./fax 81 746-97-17

e-mail:poczta@polihymnia.pl,www.polihymnia.pl 
POLSKA AKADEMIA NAUK ODDZIAŁ W LUBLINIE UNIWERSYTET MARII CURIE-SKŁODOWSKIEJ

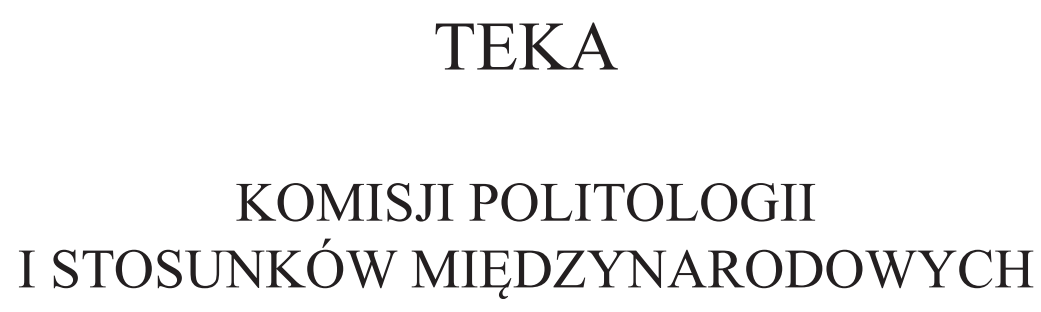

No 12/3 (2017)

Oblicza współczesnych migracji

\author{
Redaktorzy tomu \\ Katarzyna Marzęda-Młynarska \\ Agata Wiktoria Ziętek
}


POLISH ACADEMY OF SCIENCES BRANCH IN LUBLIN MARIA CURIE-SKŁODOWSKA UNIVERSITY

\title{
TEKA
}

of the COMMISSION OF POLITICAL SCIENCE AND INTERNATIONAL AFFAIRS

No 12/3 (2017)

\section{The Faces of Modern Migrations}

\author{
Redaktorzy tomu \\ Katarzyna Marzęda-Młynarska \\ Agata Wiktoria Ziętek
}




\section{CONTENTS}

\section{Katarzyna Marzęda-Młynarska, Agata Wiktoria Ziętek}

Oblicza wspótczesnych migracji

\section{Agnieszka Piekutowska, Elżbieta Kużelewska}

Migracje międzynarodowe $w$ XXI wieku. Nowe trendy $i$ wyzwania

\section{Agata Wiktoria Ziętek}

Sekurytyzacja migracji w bezpieczeństwie kulturowym Europy

\section{Katarzyna Marzęda-Młynarska}

The 2015 Migration Crisis in the European Union as a Non-Traditional

Security Challenge

\section{Magdalena Perkowska}

Nielegalna migracja w Europie - aspekty prawne i kryminologiczne

\section{Katarzyna Stachurska-Szczesiak}

Les facteurs et l'importance de la migration dans l'espace euro-maghrébin

\section{Agnieszka Nitszke}

Niemieckie ugrupowania polityczne wobec kryzysu uchodźczego

\section{Magdalena El Ghamari}

Poczatek destabilizacji regionu Bliskiego Wschodu czyli operacja 'Iracka Wolność'

- próba diagnozy konfliktu i jego skutki

\section{David Jervis}

